\title{
Ultrasound-mediated oncolytic virus delivery and uptake for increased therapeutic efficacy: state of art
}

This article was published in the following Dove Press journal:

Oncolytic Virotherapy

25 November 2015

Number of times this article has been viewed

\section{Rounak Nande' \\ Candace M Howard ${ }^{2}$ \\ Pier Paolo Claudio 3,4 \\ 'Department of Biochemistry and Microbiology, Marshall University School of Medicine, Huntington, WV, ${ }^{2}$ Department of Radiology, University of Mississippi Medical Center, Jackson, MS, ${ }^{3}$ Department of BioMolecular Sciences and National Center for Natural Products Research, School of Pharmacy, University of Mississippi, MS, ${ }^{4}$ Department of Radiation Oncology, University of Mississippi Medical Center, Jackson, MS, USA}

\begin{abstract}
The field of ultrasound (US) has changed significantly from medical imaging and diagnosis to treatment strategies. US contrast agents or microbubbles (MB) are currently being used as potential carriers for chemodrugs, small molecules, nucleic acids, small interfering ribonucleic acid, proteins, adenoviruses, and oncolytic viruses. Oncolytic viruses can selectively replicate within and destroy a cancer cell, thus making them a powerful therapeutic in treating late-stage or metastatic cancer. These viruses have been shown to have robust activity in clinical trials when injected directly into tumor nodules. However limitations in oncolytic virus' effectiveness and its delivery approach have warranted exploration of ultrasound-mediated delivery. Gene therapy bearing adenoviruses or oncolytic viruses can be coupled with MBs and injected intravenously. Following application of US energy to the target region, the MBs cavitate, and the resulting shock wave enhances drug, gene, or adenovirus uptake. Though the underlying mechanism is yet to be fully understood, there is evidence to suggest that mechanical pore formation of cellular membranes allows for the temporary uptake of drugs. This delivery method circumvents the limitations due to stimulation of the immune system that prevented intravenous administration of viruses. This review provides insight into this intriguing new frontier on the delivery of oncolytic viruses to tumor sites.
\end{abstract}

Keywords: microbubbles, ultrasound, ultrasound-contrast agent, oncolytic virus, adenovirus, gene therapy

\section{Introduction}

Our understanding of various diseases has significantly improved in recent years, leading to the emergence of potential genetic and molecular therapeutic targets ${ }^{1}$ and resulting in various successful therapies for localized cancer. However, recurrent and metastatic diseases remain poorly responsive to current treatment modalities such as surgery, radiation therapy, and chemotherapy. ${ }^{2}$ Thus, an alternative approach, such as oncolytic virotherapy, has become an attractive treatment strategy.

Oncolytic viruses such as herpes simplex virus (HSV), adenovirus (Ads), Newcastle disease virus, reovirus, vesicular stomatitis virus, measles virus, vaccinia virus, and others can be genetically modified ${ }^{3,4}$ to exhibit multiple tumor-targeting mechanisms with anticancer properties. ${ }^{5}$ These viruses can target and undergo viral replication in neoplastic cells but not in normal cells. The viral progeny directly kill the tumor cell at the end of the lytic cycle and spread throughout the tumor by infecting the neighboring cells (Figure 1), ${ }^{2}$ thus amplifying the therapeutic transgene and enhancing the therapeutic efficacy by eradicating the tumor. These characteristics make oncolytic viruses an appealing treatment modality.
Correspondence: Pier Paolo Claudio Department of Radiation Oncology, University of Mississippi Medical Center, 350 West Woodrow Wilson Drive, Suite 1600, Jackson, MS 39213, USA

Email pclaudio@olemiss.edu 


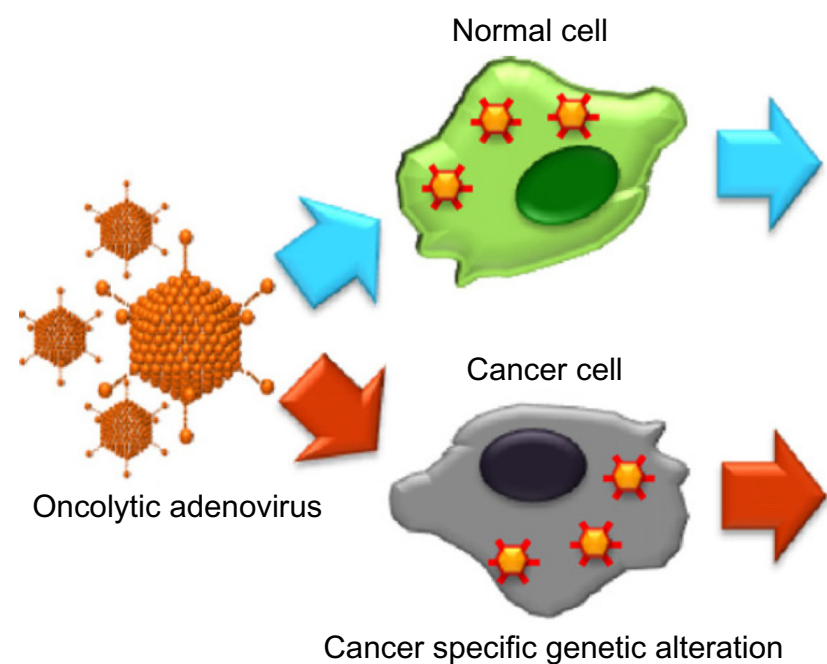

Cancer specific genetic alteration
Viral replication blocked
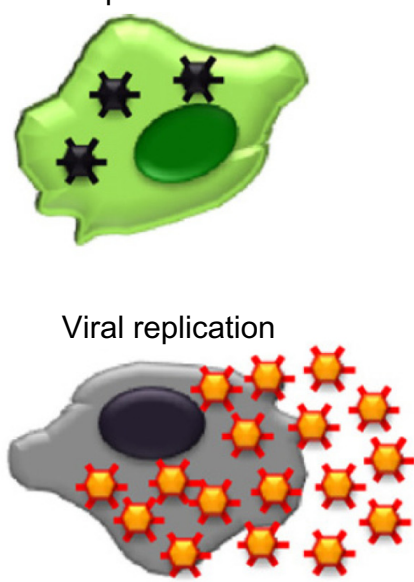

- Cell destruction

- Virus release

- Sequential viral infection

Figure I Schematic diagram of the cancer-selective killing efficacy of oncolytic Ads.

Notes: Replication-competent oncolytic Ads specifically kill neoplastic cells at the end of their lytic cycle, while sparing normal cells. The viral progeny then spread throughout a tumor, subsequently infecting and lysing surrounding cancer cells, and ultimately eliciting improved antitumor effects compared with nonreplicating Ads. Importantly, the amplification and propagation of therapeutic genes carried by the replicating viruses into neighboring tumor cells highlight the potential of replicating virus-based therapy. Reprinted by permission from Macmillan Publishers Ltd: Cancer Gene Ther. Choi IK, Yun CO. Recent developments in oncolytic adenovirus-based immunotherapeutic agents for use against metastatic cancers. 20(2):70-76. Copyright 2013. ${ }^{2}$

Abbreviation: Ads, adenoviruses.

However, results from the last decade of clinical trials with oncolytic viruses such as Ad Onyx- $015^{6}$ and CG7870 have shown that the systemically delivered viral therapeutic doses have shown poor antitumor effects as well as raised some safety concerns..$^{8-10}$ The majority of the clinical trials have been delivered by direct intratumoral injection against primary solid tumors. Systemic administration by intravenous (IV) injection has produced few successful cases with Newcastle disease virus strains (PV701 and OV001) and reovirus (Reolysin). ${ }^{8,1-14}$ There are several factors that can affect gene delivery through viral infection. ${ }^{15}$ One such obstacle exists due to the preexisting immunity against viruses in general and adenoviruses in particular that blunts the therapeutic potential. After IV delivery, adenoviruses bind with antibodies, complement, and blood cells, each restricting the viruses' efficiency. Additionally, after injection, the viral progeny must spread in the microenvironment of the tumor, which is hampered by the increased interstitial fluid pressure that arises due to the leaky vasculature and the lack of functional lymphatics. ${ }^{15-17} \mathrm{~A}$ large portion of the dose from the intratumoral injection is lost immediately due to the imprecise nature of the injection and poor penetration of the viruses that reside in the needle tract. ${ }^{11,18}$ Additional factors such as chaotic microvasculature, distribution of blood flow, dense stromal barriers, interstitial transport, and neutralization antibodies in the extracellular matrix can also limit the interstitial penetration of the viruses..$^{15,19,20}$ These factors warrant repeated injections of high volumes in an attempt to achieve uniform distribution of the viruses. ${ }^{11}$ Finally, viral vectors such as HSV may exhibit further limitation in infection and spread to neighboring cells due to their size being larger than the space between fibers in the extracellular matrix..$^{11,20,21}$ Thus, to overcome these challenges, there is a need to enhance the antitumor efficacy and to overcome the aforementioned limitations. Hence, site-directed delivery of viruses or drugs remains one of the biggest challenges in treatment of solid tumors.

Since the 1940s, ultrasonic energy has been used for diagnostic (imaging) and therapeutic (physical therapy) purposes. ${ }^{22}$ In recent years, a new therapeutic application is being explored for drug or gene delivery. There are two types of effects being produced depending on the energy delivered by ultrasound (US). High US intensities can produce a thermal effect allowing for the absorption of heat due to acoustic energy by tissues, which is employed by high-intensity focused ultrasound surgery or US-based physiotherapy. ${ }^{23}$ Alternatively, low-intensity US is nonharmful and can elicit biological effects such as cavitation, mechanical streaming, and radiation forces which are beneficial in wound healing or US-mediated delivery. ${ }^{23}$ These biological effects have been implicated in the formation of temporary pores in the plasma membrane and the vasculature, thereby allowing the diffusion or extravasation of the drug or gene at the sonoporation site. ${ }^{11,23,24}$ US efficiency is further potentiated by using US 
contrast agents (UCAs) or microbubbles (MBs) as drug or gene vectors that were originally developed for medical imaging. ${ }^{11}$ This noninvasive, safe, and effective delivery technique has been shown to increase the efficiency of gene expression from nonviral vectors such as plasmids ${ }^{25-27}$ and viral vectors such as retroviruses, ${ }^{28}$ adenoviruses, ${ }^{29-31}$ adeno-associated viruses, ${ }^{32}$ and oncolytic viruses. ${ }^{15,29,33-35}$

\section{Ultrasound}

Sound travels in waves that emanate from a source and transport energy due to the motion of the molecules. US starts at a frequency of $20 \mathrm{kHz}$, which is outside of the human audible range. It can be used for diagnostic and therapeutic applications. Most medical equipment operates in the frequency range between 1 and $15 \mathrm{MHz}$. The interaction between US and tissue is the basis of US imaging.

US uses a transducer that emanates US waves which pass through the body. The high crests and low troughs represent the specific amplitude which corresponds to the peak compressional and peak rarefactional values. These ultrasonic waves are impeded or reflected back by the organs and tissues they encounter. This echo or reflected wave is returned to the transducer, and this is converted by the computer into an image of the organ or tissue being examined. ${ }^{36}$ During the reflection, some energy (acoustic or ultrasonic energy) is transferred or attenuated from the ultrasonic wave by absorption in the form of heat or by scattering, where the energy is scattered several times back and forth before being diminished by absorption. This is dependent on the density of the medium. For example, liquid such as blood has negligible attenuation, thus it is difficult to image. ${ }^{37}$ The image developed also depends on the speed of the reflected sound waves. The acoustic waves travel at different speeds through different medium, the fastest through bone and slowest through air, so that it can be interpreted by the computer as different types of tissue. Most therapeutic applications such as physical therapy, high-frequency focused US, and ablation operate at $1 \mathrm{MHz}$, while diagnostic applications such as echocardiography and abdominal and gynecological US operate at 2.5 and $7.5 \mathrm{MHz} .^{36}$

The interaction of US with bubbles or a pocket of gas occurring in a liquid or liquid-like substance is called cavitation. ${ }^{36}$ Under ultrasonic stimulation, the bubble oscillates and pulsates differently at different ultrasonic pressure amplitudes. Below 0.1 MPa, the cavitation of the bubble pulsates (changes radius) linearly about its equilibrium state, it is called stable or noninertial cavitation; ${ }^{38}$ while at higher amplitudes (approximately 1.5 MPa), the pulsation of the bubble becomes nonlinear that stimulates a large change in the radius of the bubble. When the bubble undergoes a large expansion followed by a violent collapse due to the inertia of the inrushing liquid, it is called inertial or transient cavitation that may result in high temperatures during implosions and highly reactive free radicals may be generated. ${ }^{36,38}$ The minimum threshold required for inertial cavitation or adverse nonthermal biological effect when exposed to diagnostic US is called mechanical index (MI). ${ }^{37,38}$ US exposure can be divided into three modes with UCAs, low MI, normal MI, and high MI. Low MI is considered around 0.1 , while normal MI is considered between 0.2 and 0.7. High MI is considered to be between 0.8 and 1.9, which is considered the US Food and Drug Administration (FDA) limit. ${ }^{36}$

\section{Microbubbles}

The primary purpose of UCAs is to enhance the echogenicity of blood. Doppler is good at showing the location and motion of the rapidly flowing blood, it fails to highlight diagnostic problems such as capillary perfusion. ${ }^{38} \mathrm{UCAs}$ were developed for echocardiographic imaging to differentiate blood and the surrounding tissues by the acoustic activity or impedance, whereby MBs expands and contracts (oscillate), or ruptures, in response to US. ${ }^{23,39,40}$

UCAs or MBs are gas-filled microspheres (1-10 $\mu \mathrm{m}$ in diameter) encapsulated by a biocompatible stabilized shell. ${ }^{23,41}$ The gas core is usually filled with high-molecularweight inert gases like perfluorocarbons or sulfur hexafluoride, which decreases the solubility and diffusion of the gas, thus increasing the life span of the MBs within the circulation. The gas core can be surrounded by protein (albumin), lipid, surfactant, or biocompatible polymer shell. For example, albumin-coated MBs are formed from human serum albumin in the presence of air. The albumin shell is held together through disulfide bonds between cysteine residues formed during cavitation. ${ }^{42}$ Covalent cross-linking may explain the rigidity of the albumin shells. ${ }^{43,44}$

MBs are capable of unobstructed movement through the vasculature, including the capillaries, after IV administration. ${ }^{45}$ The ideal MB diameter is between 2.5 and $4 \mu \mathrm{m}$. This is small enough to prevent entrapment within the pulmonary capillary bed (ranging from 5 to $8 \mu \mathrm{m}$ in diameter), but big enough to capture and protect viral vectors such as Ads from the environment. ${ }^{29}$ UCAs or MBs lower the threshold for cavitation by US energy, allowing for the use of FDA-approved US devices.

MBs are typically manufactured by mechanical agitation, sonication, and microfluidic methods to engineer precise 
size distributions. ${ }^{43,46,47}$ Some popular MBs described in this review are SonoVue (SV) and Artison MBs. SV (Bracco Imaging SpA, Milan, Italy) is a UCA that is based on aqueous suspension of stabilized sulfur hexafluoride MBs. It is reconstituted from a lyophilisate with saline. Mean diameter of the MBs are $2.5 \mu \mathrm{m}$, with more than $90 \%$ of the bubbles smaller than $8 \mu \mathrm{m}$. After reconstitution, it is stable for hours and even days at room temperature. Sulfur hexafluoride is a very safe gas and is eliminated from the blood via the lungs in minutes. ${ }^{48}$ Artison MBs (Artisan Corp) are $2.5 \mu \mathrm{m}$ in diameter and are composed of a lipid shell with a perfluorocarbon gas core. The MBs are at a stock concentration of $13 \times 10^{8} \mathrm{MBs} / \mathrm{mL} .{ }^{49}$ These MBs are very echogenic and resonate like a musical instrument. ${ }^{50,51}$ These oscillations increase the cell permeability resulting in transient pores (Figure 2) in the cell membranes and the opening of tight junctions in endothelial cells ${ }^{52-56}$ facilitating the delivery of drugs into the cell. ${ }^{57-59}$ This transient pore formation is called sonoporation. ${ }^{23}$
The typical FDA-approved dose of MBs for a patient is approximately $10^{9}-10^{10} \mathrm{MBs}$ given for a $1-2 \mathrm{~mL}$ bolus IV injection. ${ }^{51,60}$ Unlike conventional MBs, a site-directed contrast agent can be designed specifically to enhance both target-specificity and drug delivery capabilities. ${ }^{61}$ The physical and chemical design of UCAs can be manipulated such that synthetic surfactant, tuning of size, composition, degradability, surface properties, and biofunctionality ${ }^{62}$ can be optimized for incorporating genetic and nongenetic material into the MB. Figure 3 summarizes some of these different approaches that can be taken to make MBs incorporating drugs. The advantages of this approach are that US-targeted MBs release the drugs upon cavitation and deliver the drug locally into the tumor site. This is called US-targeted MB destruction. Upon interaction with the US, MBs may explode or cavitate imparting a ballistic-like effect, driving the drug from the vasculature into or through the vessel wall. Thus the therapeutic potential of drug delivery and drug action is increased.
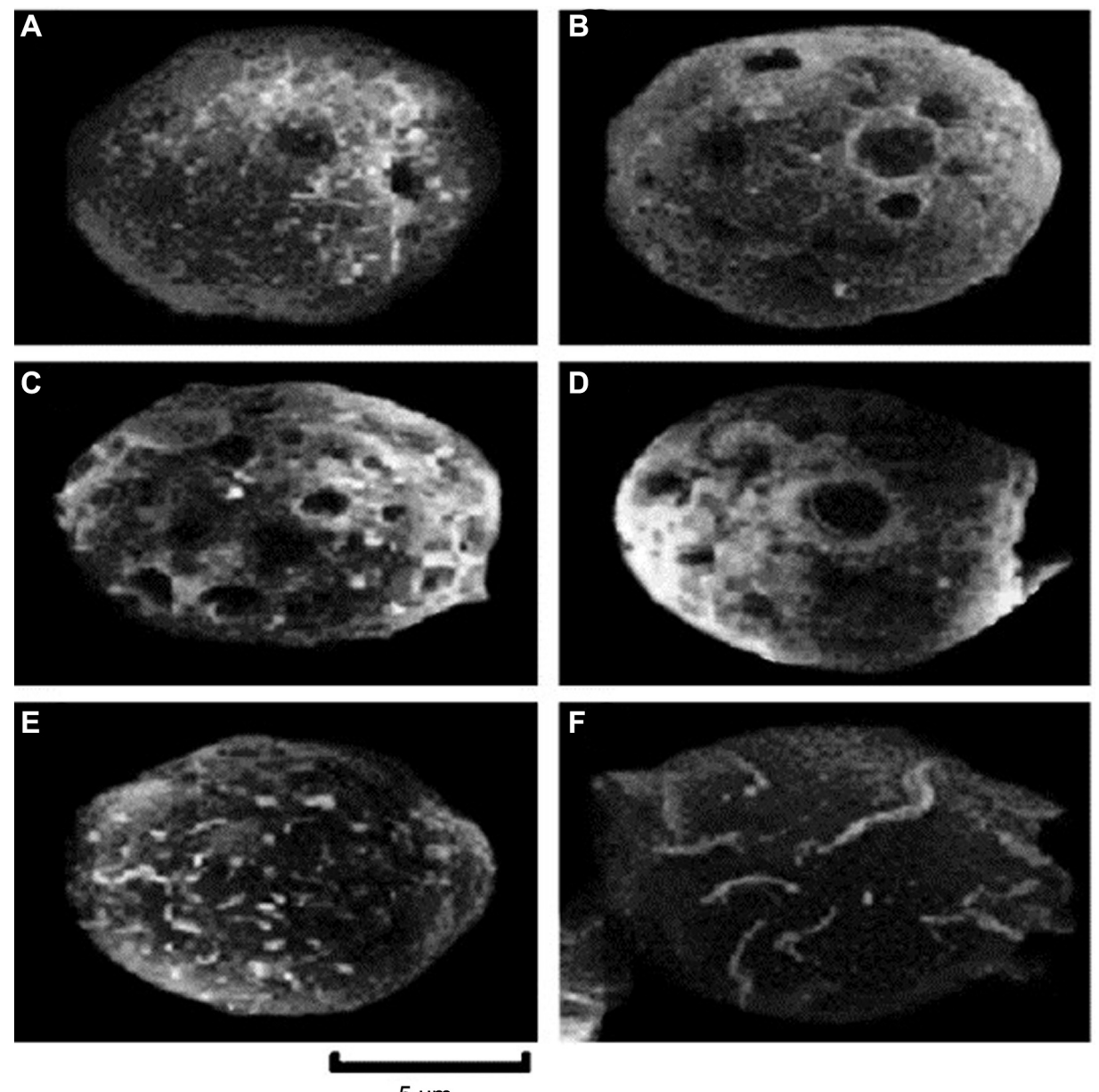

$5 \mu \mathrm{m}$

Figure 2 Scanning electron microscopic images of HL-60 cells exposed to US in the presence of MBs.

Notes: Scanning electron microscopic images of HL-60 cells exposed to US in the presence of MBs (A-D), irradiated with US alone (F) or untreated (E). Reproduced with permission from Tinkov S, Bekeredjian R, Winter G, Coester C. Microbubbles as ultrasound triggered drug carriers. J Pharm Sci. 2009;98:1935-196I with permission from John Wiley and Sons. ${ }^{72}$

Abbreviations: MBs, microbubbles; US, ultrasound. 

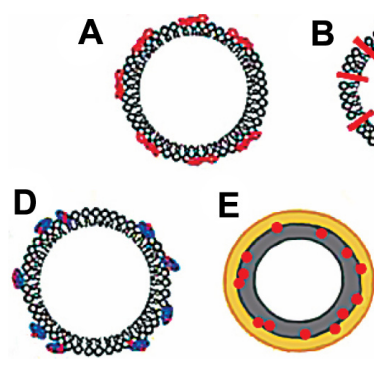
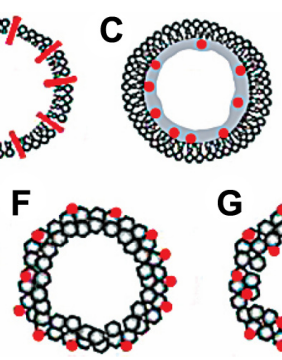

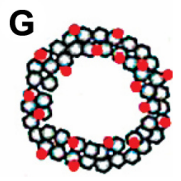

Figure $3 \mathrm{MB}$ structure classes and drug-load localizations (in red).

Notes: (A) Attachment to the outer shell surface, (B) intercalation between monolayer phospholipids, (C) incorporation in a layer of oil, (D) complexes with smaller particles (secondary carriers), (E) physical encapsulation in a polymer layer (gray) and coating with biocompatible material (yellow), (F) surface loading of protein-shelled MBs, (G) entire volume loading of protein-shelled MBs. Reproduced with permission from Tinkov S, Bekeredjian R, Winter G, Coester C. Microbubbles as ultrasound triggered drug carriers. J Pharm Sci. 2009;98:1935-1961.72

Abbreviation: $\mathrm{MBs}$, microbubbles.

\section{Microbubble and cell interactions}

MBs oscillate in the presence of US, and the resulting changes in the MB causes biological effects on the surrounding vascular membrane or plasma membrane of cells. When MBs oscillate near the plasma membrane, it leads to the phenomena called "push and pull" and "microbubble jetting". ${ }^{63-65}$ At low acoustic amplitudes, MBs expand and push against the cell membrane causing the membrane to be pulled apart. Alternatively, when MBs contract they pull the cell membrane toward the MB. When MBs attach to the cell membrane, they create enough shear to rupture the membrane due to fluid streaming around the oscillating bubbles. ${ }^{23}$ This phenomenon is called microstreaming. In contrast, when the MBs experience inertial cavitation, the resulting shock wave leads to pore formation. ${ }^{66}$ Figure 4 shows the MBs undergoing the abovementioned changes during US stimulation resulting in MBs entering into the cell. ${ }^{23,66,67}$ At higher acoustic amplitudes, microjets can cause shear stress on the cell membrane and create transient, nonlethal holes in the plasma membrane, through which a drug or gene is able to diffuse. ${ }^{45}$

Pore formation is essential for US-mediated delivery. Scanning electron microscopy studies have shown that US causes pores that range in size from 30 to $100 \mathrm{~nm}$ and up to a few micrometers (Figure 2). ${ }^{23,68}$ Flow cytometry studies with the $75 \mathrm{~nm}$ sized fluorescent nanospheres have confirmed the formation of pores on the membrane..$^{23}$ The pores have a transient character and reseal quickly after a few seconds ${ }^{69}$ or minutes ${ }^{70}$ by an endogenous vesicle-based healing response ${ }^{68}$ with the aid of $\mathrm{Ca}^{2+}$ and ATP. ${ }^{57,71}$ The development of pores is limited to the cell membrane, and most reports indicate that it does not affect the nucleus apparently because the highly viscous cytoplasm prevents its direct perturbations. ${ }^{68,72}$ The pore closure time has been estimated at 5 seconds after

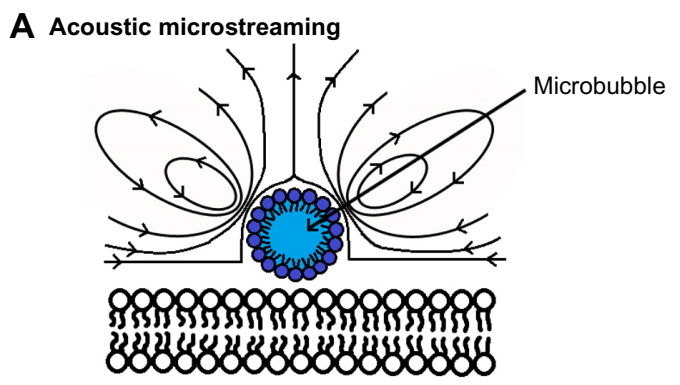

B Bubble oscillations

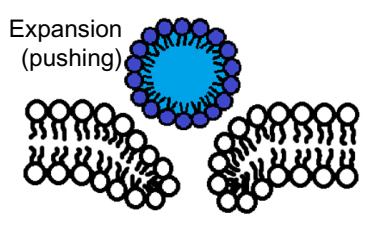

C Intertial cavitation shockwave
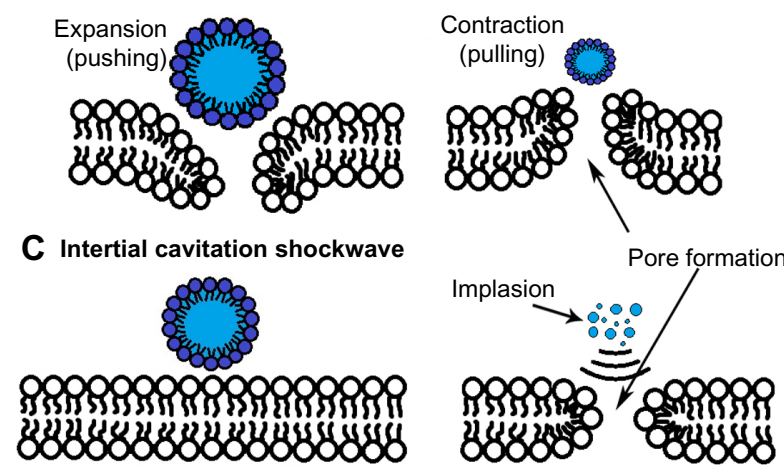

D Micro-jet formation

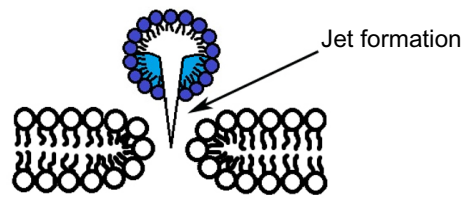

Figure 4 Sonoporation mechanisms by microbubbles.

Notes: Sonoporation occurs when microbubbles are in close proximity to the cells. The interaction between microbubble and cell membrane creates transient pores by (A) acoustic microstreaming associated with stable cavitation, (B) bubble oscillations, (C) shock waves created by inertial cavitation and lastly, (D) microjet formation that punctures pores in the phospholipid bilayer or membrane of a cell.

the US stimulation by flow cytometry and patch clamp experiments. $23,59,73$

Some studies have reported the generation of intracellular reactive oxygen species following US that may contribute to the permeabilization of the membrane without affecting cell viability. ${ }^{45,72,74,75}$ Some have also reported the involvement of intracellular calcium entrance in active transport mechanisms, such as clathrin-mediated endocytosis and phagocytosis in the uptake of $\mathrm{MBs},{ }^{57,76-78}$ and the fusion of lipid-based MBs with the phospholipid cell membrane. ${ }^{45}$ Several studies have suggested that hydrogen peroxide $\left(\mathrm{H}_{2} \mathrm{O}_{2}\right)$ production after sonoporation could be related to the cavitation phenomenon. ${ }^{75,79,80}$ US affects the electrophysiological cell activities by modulating the ion-channel conductance and mechanical stress-associated stretch activated channels. ${ }^{81}$ In addition to the effects on a cellular level, UTMD affects the microvasculature too. It has been shown that UTMD transiently increases capillary permeability. Depending on 
US energy, MB concentration, and duration of treatment, this phenomenon can even lead to hemorrhage..$^{72}$

\section{Delivery of oncolytic virus mediated by ultrasound and microbubbles (in vitro)}

Most in vitro studies on the delivery of oncolytic viruses have been performed using cells in a monolayer and a few studies cells in suspension. Okunaga et $\mathrm{al}^{11}$ and Shintani et a $\mathrm{a}^{15}$ have demonstrated in vitro the effects of US with MB delivery of the HSV type-1 (HSV-1) oncolytic viruses R849 $9^{15}$ and $\mathrm{RH} 2^{11}$ in human oral squamous cell carcinoma SAS cells ${ }^{11,15}$ and Vero monkey kidney cells. They used Artison MBs that have a lipid shell filled with perfluorocarbon gas to enhance the uptake of HSV-1 viruses and formation of plaques. They demonstrated after a period of viral absorption, an increase in the uptake of HSV-1 and plaque number with a 10-seconds US exposure. The plaque number was 3.6-fold greater in UStreated cells than the control. ${ }^{11}$ US with MB showed a further increase by 4.6 -fold in the number of plaques. Prolonging the exposure showed decreasing effect that may result from disruption of cell viability or virus integrity (Figure 5). ${ }^{11,15}$ US exposure can also affect the cell morphology and cell viability by causing heat. Heat production mostly depends on the intensity, duty cycle, and duration of US exposure. Intensity at $2.0 \mathrm{~W} / \mathrm{cm}^{2}$ and higher is known to cause cell damage. ${ }^{15} \mathrm{US}$ and MB studies are normally performed below intensity of $2.0 \mathrm{~W} / \mathrm{cm}^{2}$; as such there has been no study that has observed any detrimental effects on virus stability and replication.

The aforementioned in vitro studies have limited clinical relevance given the challenges observed in a solid tumor environment. ${ }^{34,79,82,83}$ Bazan-Peregrino et $\mathrm{al}^{34}$ developed a tumor-mimicking flow vessel model for breast cancer BT-474 cells with flowing oncolytic AdEHE2F-Luc, which expresses the luciferase as a transgene to mimic perfusion for testing the extravasation of the drugs into a tissue-mimicking material. They demonstrated that the viral particle content increased 2-fold in the presence of stable cavitation and 4-fold in inertial cavitation of SV MBs with real-time polymerase chain reaction. They also analyzed luciferase transgene expression 24-hours after the delivery of the viral particles and US. They demonstrated a 10 -fold increase in luciferase expression induced by stable cavitation and a 200 -fold increase induced by inertial cavitation. They also performed a viral distribution study and found that the number of infected cells around the vessels increased more for inertial cavitation (60 times) than stable cavitation (10 times) in the direction of the US beam up to $2 \mathrm{~mm}$ away from the vessel-like structure. Finally, cell viability was also observed after transfection with AdEHE2F-Luc following US, which demonstrated no significant cell death by virotherapy for stable cavitation, while inertial cavitation demonstrated 55\% cell death in the tumor-mimicking flow-vessel model. ${ }^{34}$

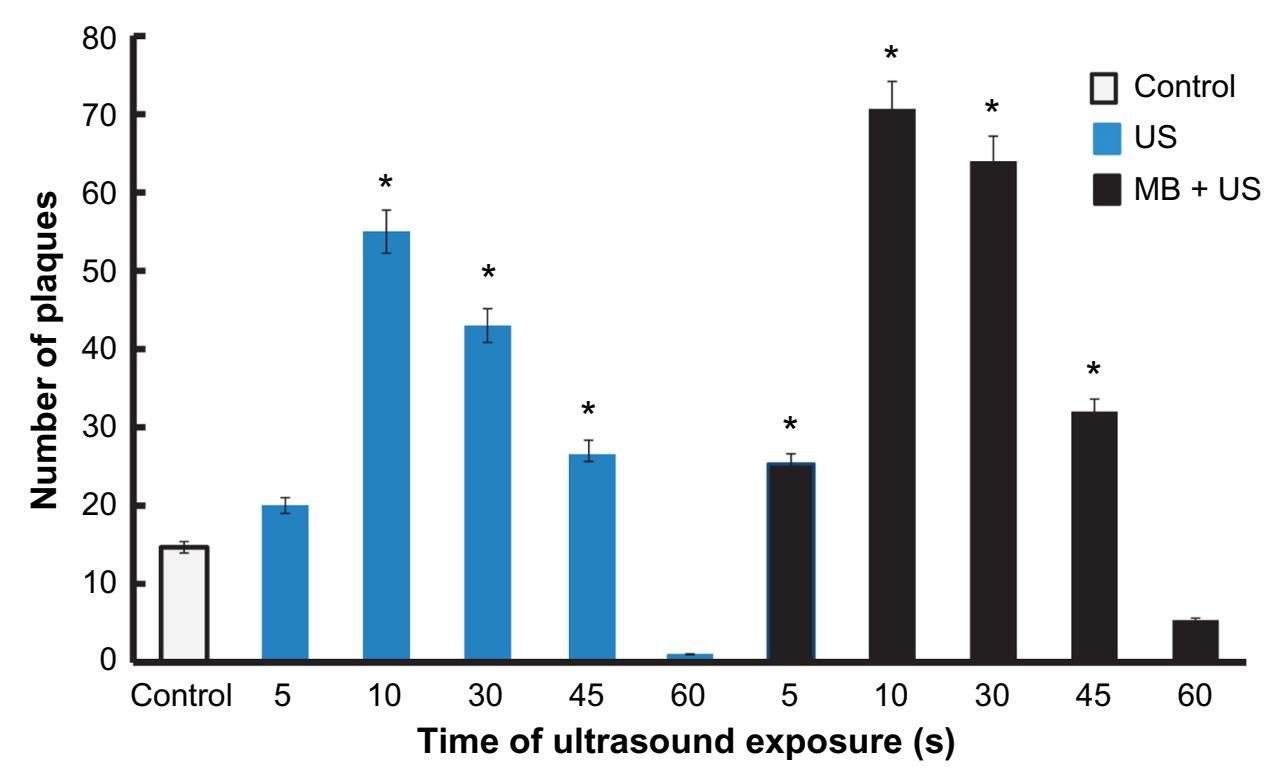

Figure 5 Effects of US on HSV type-I plaque formation.

Notes: SAS cells were inoculated with 100 plaque-forming units of $\mathrm{RH} 2$ and incubated at $37^{\circ} \mathrm{C}$ for 30 minutes. Thereafter, cells were exposed to US at an intensity I W/ $\mathrm{cm}^{2}$ and a $20 \%$ duty cycle for 10-60 seconds in the presence or absence of MBs at room temperature. The cells were washed with phosphate-buffered saline to remove any unbound virus and covered with medium containing methylcellulose. For the plaque assay, these cells were cultured at $37^{\circ} \mathrm{C}$ for approximately 48 hours. Data are mean \pm SD of six determinations. * $<0.01$ significantly different from the control. Reprinted by permission from Macmillian Publishers Ltd: Cancer Gene Ther. Okunaga S, Takasu A, Meshii N, et al. Ultrasound as a method to enhance antitumor ability of oncolytic herpes simplex virus for head and neck cancer. 22(3):163-I68. Copyright 20I5."

Abbreviations: HSV, herpes simplex virus; MB, microbubble; SD, standard deviation; US, ultrasound. 
Their experiments show that US could have little to no effect on cell viability under ordinary conditions and significant increase in the uptake of adsorbed viral particles by US with MBs. Bazan-Peregrino et $\mathrm{al}^{34}$ demonstrated the penetration of the oncolytic virus away from the vessel-like structure and that inertial cavitation is far more effective than stable cavitation in enhancing the delivery, distribution, and efficacy of oncolytic viruses. However, there are limitations even with this model as it does not accurately depict extracellular matrix or the high interstitial fluid pressure that acts as a barrier to tumor drug delivery in vivo. Finally, an immune response against the virus that is always activated following IV injection ${ }^{34}$ cannot be accounted for by this model.

\section{Intratumoral delivery of oncolytic virus mediated by ultrasound and microbubbles (in vivo)}

Intratumoral injections versus IV injections have their own benefits and limitations, and we will discuss them further. We will first explore the effects of intratumoral injections of oncolytic virus in combination with MBs and US. Previous studies conducted by Takaoka et al, ${ }^{84}$ Carlisle et al, ${ }^{33}$ and Greco et $\mathrm{al}^{29}$ have demonstrated that when oncolytic viruses are injected directly in a tumor, the expression of the oncolytic virus is limited to a portion of the tumor even if the injected volume is sufficient to cover the entire tumor. In order to circumvent the limitation of viral distribution observed, Okunaga et $\mathrm{a}^{11}$ have demonstrated the effects of HSV-1 RH2 viruses in combination with US and MBs in BALB/c nude mice bearing human squamous cell carcinoma SAS tumor xenografts. Okunaga et $\mathrm{al}^{11}$ have shown an increase in the viral titer from $2.3 \times 10^{4}$ for the control to $4.38 \times 10^{4} \mathrm{PFU}$ (plaque-forming unit) (RH2 viruses with US group) at the sonoporated tumor site delivered without MBs. However, injections of RH2 viruses mixed with MBs and subsequent exposure to 10 seconds US showed an increase in viral titer to $10.5 \times 10^{4} \mathrm{PFU}$ per tumor. Okunaga et al $^{11}$ also determined the tumor size in 24 days following treatment with RH2 viruses with MB and US in comparison to the control or RH2 viruses and US group and found the tumor size to be significantly suppressed, indicating the enhancing effect of US in the presence of MBs (Figure 6). Similarly, Bazan-Peregrino et $\mathrm{al}^{10}$ also tested the intratumoral delivery of Ad-GFP (green fluorescent protein) coinjected with MBs with US. They demonstrated that following the application of US, tumors showed elevated level (6.5-fold increase) and improved spatial distribution (5-fold increase) of the viral transgene expression, relative to the tumor that did not receive any US. Thus, it can be inferred that the cavitation event of the MB in the presence of US can enhance transgene expression of Ad by improving its bioavailability and intratumoral biodistribution. ${ }^{10}$

As previously noted, intratumoral delivery efficiency is limited as the oncolytic viruses do not spread throughout the tumor and are mostly relegated to the injection tract

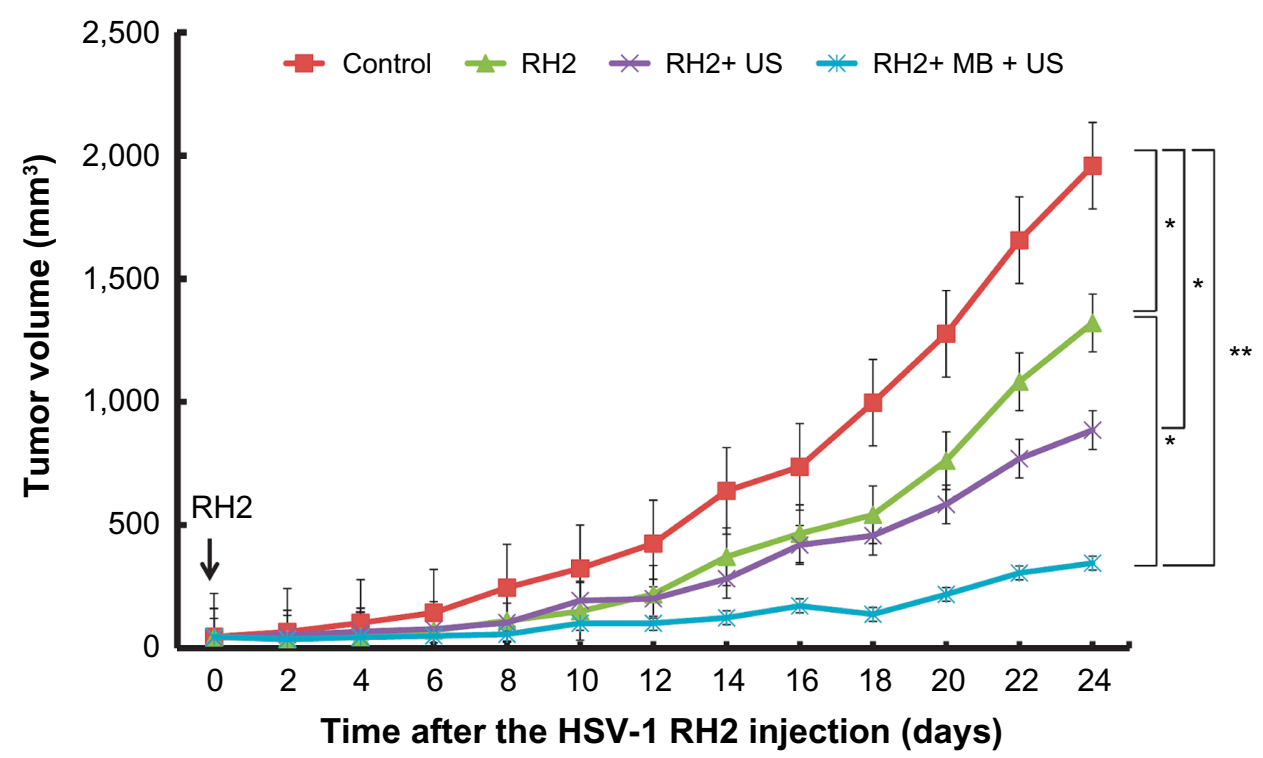

Figure 6 Effects of HSV-I RH2 and US on the growth of oral SCC xenografts in nude mice.

Notes: Nude mouse tumors were injected with HSV-I RH2 with or without MBs and then exposed to US. Control animals were given phosphate-buffered saline intratumorally instead of HSV-I. The experimental groups were as follows: untreated control, $\mathrm{RH} 2$ injection only (RH2), $\mathrm{RH} 2$ injection and US exposure (RH2+ US), and RH2 and MBs injection and US exposure ( $\mathrm{RH} 2+\mathrm{MB}+\mathrm{US})$. Tumor volumes were measured during the experiment. Data are the mean $\pm \mathrm{SD}$ of four tumors in each group. $* P<0.05$, $* * P<0.01$. Reprinted by permission from Macmillian Publishers Ltd: Cancer Gene Ther. Okunaga S, Takasu A, Meshii N, et al. Ultrasound as a method to enhance antitumor ability of oncolytic herpes simplex virus for head and neck cancer. 22(3):163-168. Copyright 2015."'

Abbreviations: HSV-I, herpes simplex virus type-I; MB, microbubble; SCC, squamous cell carcinoma; SD, standard deviation; US, ultrasound. 


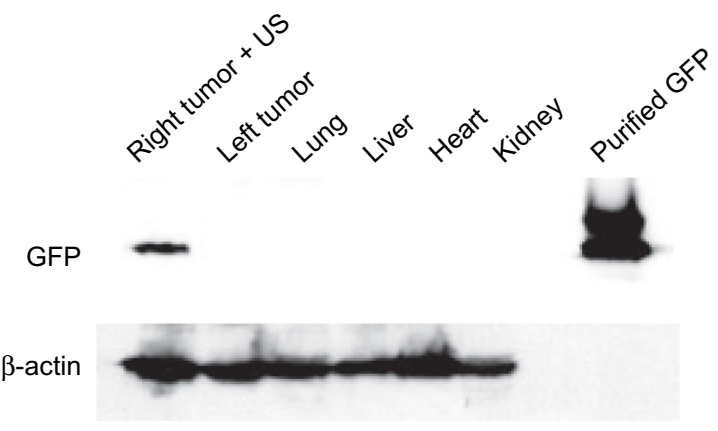

Figure 7 Western blot analysis of Ad-GFP/microbubble-transduced DU-I45 tumor xenografts.

Notes: Immunoblot showing the expression levels of GFP in DU-145 cells, following US-targeted microbubble/Ad transduction of GFP at 96 hours. Only the tumor on the right flank was sonoporated for 10 minutes, resulting in the delivery and expression of GFP. The left tumor, heart, lung, liver, and kidney were negative for GFP expression. Purified glutathione-S-transferase-GFP was used as a positive control. Protein gel loading was normalized using $\beta$-actin as a control. Reprinted by permission from Macmillan Publishers Ltd: Mol Ther. Greco A, Di Benedetto A, Howard CM, et al. Eradication of therapy-resistant human prostate tumors using an ultrasound-guided site-specific cancer terminator virus delivery approach. I8(2):295-306. Copyright 2010. ${ }^{29}$

Abbreviations: Ad, adenoviruses; GFP, green fluorescent protein; US, ultrasound.

sites. The microenvironment of the tumors allows some of the injected viruses to wash out during the process of binding to the cell surfaces and entering blood vessels, thereby reducing the antitumor activities of the injected oncolytic viruses. ${ }^{84}$ Inactivating antibodies can sequester and inactivate the injected viruses, thus lowering their potential. To investigate whether US could increase the number of infected cells, Okunaga et $\mathrm{al}^{11}$ measured the viral antigen positive area. They observed that tumors treated with US and MBs showed greater antigen-positive area than those treated with RH2 viruses only, thus demonstrating that more cells were inoculated with HSV-1 RH2 viruses by US, which replicated at the tumor site, ${ }^{11}$ and thereby improving the overall efficacy of intratumoral injections.

\section{Intravenous delivery of oncolytic virus mediated by ultrasound and microbubbles (in vivo)}

No systemic delivery system exists that can enhance infection of Ads by more than a factor of six, regardless of the genetic and chemical modifications of viral capsid ${ }^{85,86}$ or the vascular permeabilizing protein ${ }^{87}$ being used. ${ }^{10}$ This is due to the chaotic and tortuous nature of tumor-associated vessels, which results in the tumor supply being highly heterogeneous, leaving many regions poorly perfused even though enhanced permeability and retention effect in tumor vasculature assists the uptake of oncolytic viruses passively. ${ }^{86,88}$ This makes the delivery of oncolytic viruses nonuniform and its efficacy difficult to predict. ${ }^{89,90}$ Finally, Ad clearance is rapid with less than $0.5 \%$ of the dose still circulating at 30 minutes. ${ }^{33}$ Thus, there is a pressing need to enhance the delivery of oncolytic virus into the tumor. ${ }^{10}$ Several studies were carried out to prove that US-mediated MB delivery of oncolytic viruses could overcome the factors that limit their clinical efficacy. ${ }^{10,29,33}$

The first study on systemic MB-assisted and US-mediated oncolytic viral delivery was carried out by Greco et al, ${ }^{29}$ in which conditionally replicative Ad under the progressionelevated gene-3 promoter ( $P E G-3)$ carrying the therapeutic gene melanoma differentiation associated gene-7/interleukin-24 ( $m d a-7 / I L-24)$, the Ad.PEG-E1A-mda-7, or cancer terminator virus (CTV) was delivered by a Targeson lyophilized lipid-encapsulated perfluorocarbon MBs/UCA to xenografted human prostate cancers DU145 and therapy-resistant DU-Bcl$\mathrm{xL}$ in nude mice. In this work, it was demonstrated that the US/MB delivery system efficiently targeted Ad-GFP only to the sonoporated tumors. No other organs were infected with Ad-GFP (Figure 7). A complete eradication of the CTV.mda7+ $\mathrm{MB}+\mathrm{US}$ treated tumors on the right flank was observed (Figure 8). Similarly, a dramatic reduction in tumor size was also observed for the Ad.mda-7/IL-24+ MB + US treated tumors on the right flank (Figure 8). Oddly, the left flank or nontreated tumor also showed reduction in tumor size due the expression of protein mda-7, a cytokine (Figure 8). It was also worth noting that the effect observed using the systemic MB/ US approach with CTV.mda-7 greatly exceeded that observed following intratumoral injection with CTV.mda-7. ${ }^{29}$ US in combination with the MBs greatly increased the expression of mda7 in the sonoporated tumor in comparison to the nontreated tumor (Figure 8). The aforementioned study showed the impressive therapeutic potential of the CTV oncolytic virus delivered by MB and targeted by US; however, no information regarding the underlying US mechanism, quantification of the accumulation, and spatial distribution of the oncolytic virus was reported.

Bazan-Peregrino et $\mathrm{al}^{10}$ answered these questions with the delivery of another oncolytic virus, the AdEHE2F-Luc virus, in combination with US and MBs, to estrogen receptor positive ZR75.1 human breast cancer xenograft tumors. They reported that stable cavitation of MBs at $360 \mathrm{kPa}$ of US did not result in any luciferase expression, but inertial cavitation with $1.2 \mathrm{MPa}$ significantly raised the luciferase expression in comparison to untreated tumors. This showed that the virus extravasated and infected the cancer cells. They also showed that hotspots of luminescence appeared in tumors exposed to $1.2 \mathrm{MPa}$ of focused US, which suggested that the luciferase transgene was expressed only in the tumor demonstrating the specificity of 


\section{DU-145}
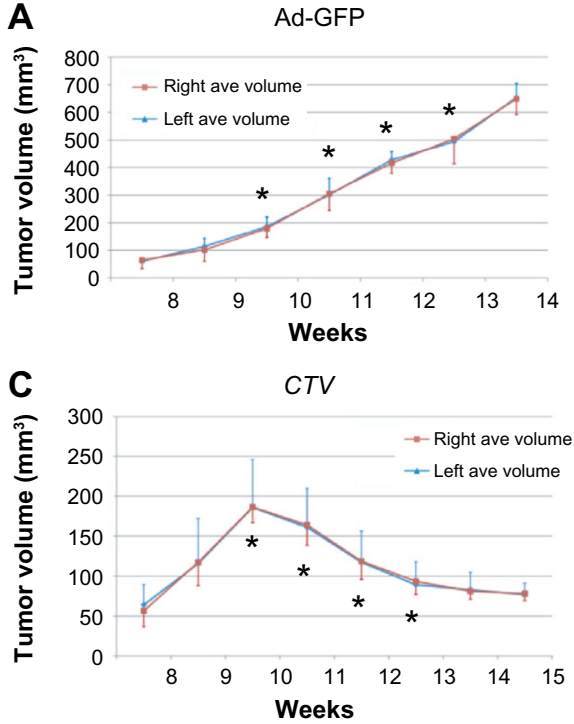

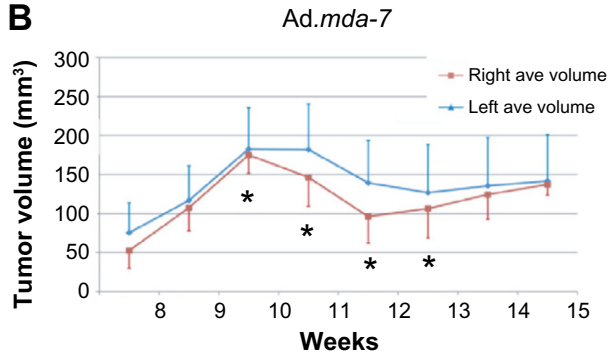

D

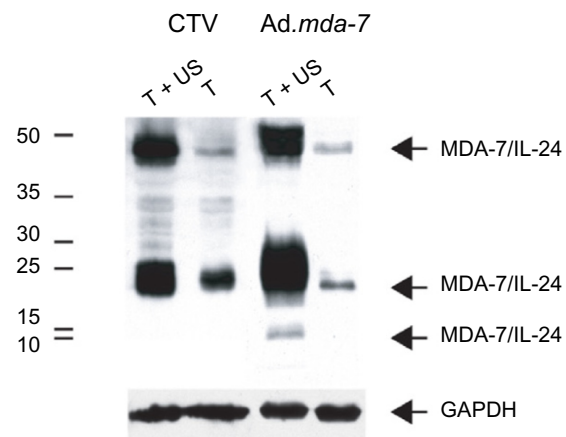

\section{DU-Bcl-xL}

E

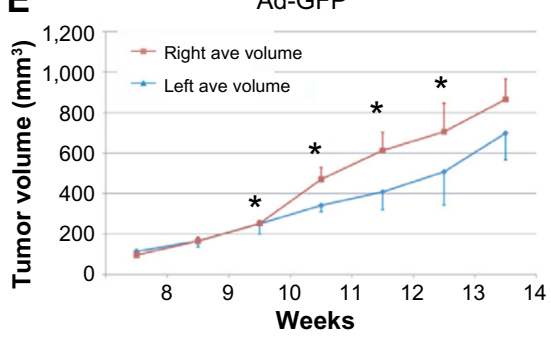

G

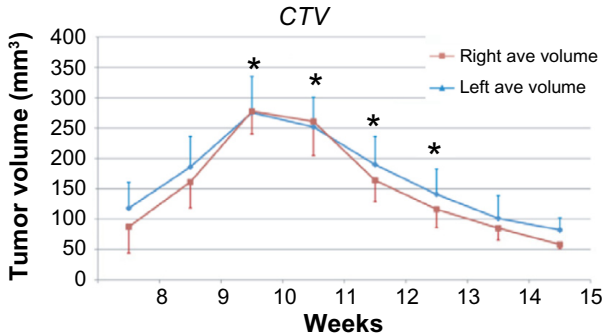

$\mathbf{F}$

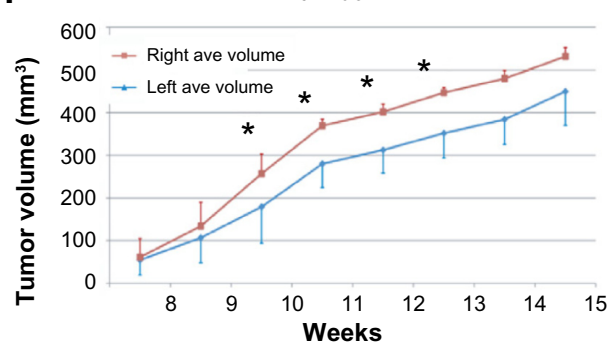

H CTV Ad.mda-7

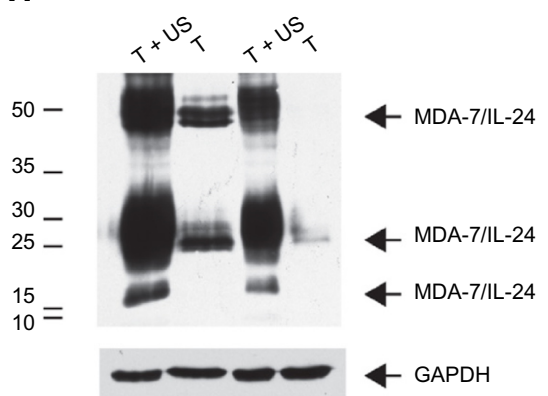

Figure 8 Growth curves and Western blot analysis of large DU-I45 and DU-Bcl-xL tumor xenografts treated with microbubble encapsulated Ad-GFP, Ad.mda-7, or CTV (Ad.PEG-EIA-mda-7) and treated with US in the right tumor.

Notes: Subcutaneous tumor xenografts from DU- I45 and DU-Bcl-xL were established in athymic nude mice in both right and left flanks, and only tumors on the right side were sonoporated following tail vein injection of the indicated microbubble/Ad complexes during a course of 4 weeks. Tumor treatments were initiated when tumors reached a size of 250-350 $\mathrm{mm}^{3}$. Asterisks point at treatment times. (A) Measurement of GFP-treated DU-I 45 tumor volumes. The data represent mean \pm SD with at least five mice in each group. (B) Measurement of Ad.mda-7-treated DU-I 45 tumor volumes. The data represent mean \pm SD with at least seven mice in each group. (C) Measurement of CTVtreated DU-I45 tumor volumes. The data represent mean \pm SD with at least seven mice in each group. (D) Western blot analysis of protein extracts from representative DU- 145 tumor samples treated with Ad.mda-7 or CTV. The immunoblot was reacted with anti-MDA-7/IL-24. Arrowheads point at the various glycosylated forms of MDA-7/ IL-24. Protein gel loading was normalized using anti-GAPDH as a control. (E) Measurement of GFP-treated DU-Bcl-xL tumor volumes. The data represent mean \pm SD, with at least five mice in each group. (F) Measurement of Ad.mda-7-treated DU-Bcl-xL tumor volumes. The data represent mean \pm SD, with at least seven mice in each group. (G) Measurement of CTV-treated DU-Bcl-xL tumor volumes. The data represent mean \pm SD with at least seven mice in each group. $(\mathbf{H})$ Western blot analysis of protein extracts from representative DU-Bcl-xL tumor samples treated with Ad.mda-7 or CTV. The immunoblot was reacted with anti-MDA-7/IL-24. Arrowheads point at the various glycosylated forms of MDA-7/IL-24. Protein gel loading was normalized using anti-GAPDH as a control. Reprinted by permission from Macmillan Publishers Ltd: Mol Ther. Greco A, Di Benedetto A, Howard CM, et al. Eradication of therapy-resistant human prostate tumors using an ultrasound-guided site-specific cancer terminator virus delivery approach. 18(2):295-306. Copyright 2010.29

Abbreviations: Ad, adenovirus; ave, average; CTV, cancer terminator virus; GFP, green fluorescent protein; SD, standard deviation; US, ultrasound. 
combining US and oncolytic virus. They demonstrated that the $\mathrm{MB} / \mathrm{US}$ delivery system could enhance the IV delivery system of an oncolytic Ad into the tumor up to 50-fold. Similarly, Carlisle et $\mathrm{al}^{33}$ demonstrated that following the IV injection of polymer-coated (stealth) luciferase Ad (PC-Ad) with SV MBs and US, the luciferase expression increased 20-fold by day 2 and 30 -fold by day 3 . This dramatic change shows an increase in virus activity and an improved access to low $\mathrm{pH}$ and hypoxic environments. ${ }^{33,91}$ The AdEHE2F-luc in vivo study by Carlisle et $\mathrm{a}^{33}$ showed a statistically significant higher luciferase expression (400-fold) and higher virus genome content (200-fold) in the PC-Ad with MBs and US group compared to all the other treatment groups. Conversely, tumors treated with PC-Ad and SV MBs, but without US showed staining of the virus at the vasculature, while tumors treated with PC-Ad and SV MBs and US showed viral staining at more than $100 \mu \mathrm{m}$ from the vasculature, thereby demonstrating the increased penetration potential of viruses by US and MBs. Both Bazan-Peregrino et $\mathrm{al}^{10}$ and Carlisle et $\mathrm{al}^{33}$ demonstrated that US and SV MBs produced no increase in the total amount of oncolytic viruses entering the tumors treated with US or non-US tumors with just $0.08 \%$ of dose accumulating with or without US and SV MBs. Thus, US-induced enhancements of oncolytic virus activity can result from improved intratumoral spread/bioavailability as there is no increase in the total amount of oncolytic viruses entering the tumor. ${ }^{10}$ It is commonly believed that without US, a plateau in the number of Ads in tumor xenografts is reached suggesting that both initial dose and distribution of Ad ultimately determine the tumor's fate. However, enhanced uptake and penetration of PC-Ad and SV MBs with US provides a method to break through this plateau unhindered by spatial or resource restrictions, thereby allowing for lower doses of virus needed to achieve tumor growth retardation. ${ }^{33}$

\section{Conclusion: state of art}

Bazan-Peregrino et $\mathrm{l}^{10}$ found that the half-life of the MBs in the bloodstream is approximately 80 seconds, which interestingly is similar to the half-life of the oncolytic adenovirus that is approximately 120 seconds. ${ }^{10}$ The immunogenic nature of human Ads and most oncolytic viruses limits its use to intratumoral injection route in gene transfer. Ad transfection is further hampered by the fluctuating presence of coxsackie and adenovirus receptor and integrins on the cell surface. To circumvent these limitations, a novel approach was developed in Dr Claudio's lab, wherein viruses are encapsulated inside the shell of a lyophilized lipid-encapsulated perfluorocarbon MB/UCA, which acts as delivery vehicle for a site-specific gene or viral release and transfer system. Greco et $\mathrm{al}^{29}$ have clearly shown the advantage of this type of delivery system in an immune-deficient mice model. The MBs encapsulating the Ads are capable of protecting the Ads from degradation by the immune system and was proven by Dash et $\mathrm{al}^{12}$ in an immune-competent animal study. The benefit of this approach is that any viral species could be potentially protected from the immune system until US is applied, resulting in the complete tumor infection and maximizing its antitumor properties. This new technology allows for the use of the IV route, which was once considered problematic, as MBs protect the viral payload from rapid degradation by the host's immune system, thus bringing new hope to the frontier of gene therapy and its use in clinical settings.

Most other studies have coinjected MBs with oncolytic viruses, thereby exploiting the cavitation and penetration properties of the MBs. However, the biggest disadvantage of this distinct approach is that the oncolytic viruses that are systemically administered do not have protection from the immune system and will be degraded before they reach the tumor. The benefit of focusing US at the diseased site is to cause the cavitation of MBs that imparts a ballistic or shockwave-like effect, which enhances the uptake of incorporated drugs. It is believed that oscillating MBs and other acoustic forces induce gaps between endothelial cells, ${ }^{93,94}$ thus allowing for extravasation of molecules/drugs through the blood vessels to the specific tissue. ${ }^{95}$ The time window of extravasation is dependent on the extravasating molecules rather than the gap size. ${ }^{96}$ These drugs are delivered at a lower concentration, yet they achieve therapeutic effect. We have tried to emphasize the potential of site-specific therapeutics to cancer treatment.

US is an inexpensive, noninvasive, and readily available modality. However, US-mediated delivery is still in its infancy. There are still challenges that need to be overcome in order to improve its efficiency and clinical translation. Viruses and DNA plasmids that are taken up by the cells need to overcome the cell machinery such as escape from the endosome system and need to be transported to the nucleus in order to be effective. ${ }^{23}$ Additionally, US-mediated delivery is limited to predetermined/ diagnosed site of the disease or metastasis. Unseen metastasis cannot be treated unless the drug that is coupled with this delivery system has a residual/complementary effect or is triggered after primary delivery. Multiple diseased sites can also be treated with US-mediated delivery if an infusion of the MBs and drug is administered rather than a bolus injection.

MBs are ever evolving as there are different targeting ligands being incorporated into acoustically active materials for cellspecific delivery. ${ }^{51}$ These ligands are being designed to target different diseased organs, clots, cancerous cells, and angiogenesis. 
Thus US-mediated delivery could represent an endless benefit to the field of medicine and cancer therapeutics.

However, inertial cavitation of MBs leads to some unavoidable collateral damage, ${ }^{97,98}$ such as microvascular leakage accompanied by capillary damage, and erythrocyte extravasation with resulting edema and inflammation..$^{38,47,96}$ Therefore, further studies are required before US-mediated gene or viral delivery will be ready for clinical trials. Successful studies using immune-competent animals are also required in order to demonstrate the potential clinical use of this delivery system. To date there have only been a limited number of oncolytic viruses which were studied in conjunction with US-mediated MB delivery. This delivery approach can also be generally applied to all other viral species to significantly enhance their therapeutic efficacy and circumvent the known barriers.

\section{Disclosure}

The authors report no conflicts of interest in this work.

\section{References}

1. Juffermans LJ, Meijering DB, van Wamel A, et al. Ultrasound and microbubble-targeted delivery of therapeutic compounds: ICIN Report Project 49: drug and gene delivery through ultrasound and microbubbles. Neth Heart J. 2009;17(2):82-86.

2. Choi IK, Yun CO. Recent developments in oncolytic adenovirus-based immunotherapeutic agents for use against metastatic cancers. Cancer Gene Ther. 2013;20(2):70-76.

3. Tong AW. Oncolytic viral theray for human cancer: challenges revisited (review). Drug Devel Res. 2006;66:260-277.

4. Tong AW, Senzer N, Cerullo V, Templeton NS, Hemminki A, Nemunaitis J. Oncolytic viruses for induction of anti-tumor immunity. Curr Pharm Biotechnol. 2012;13(9):1750-1760.

5. Choi JW, Lee JS, Kim SW, Yun CO. Evolution of oncolytic adenovirus for cancer treatment. Adv Drug Deliv Rev. 2012;64(8):720-729.

6. Hamid O, Varterasian ML, Wadler S, et al. Phase II trial of intravenous CI-1042 in patients with metastatic colorectal cancer. J Clin Oncol. 2003;21(8):1498-1504.

7. Small EJ, Carducci MA, Burke JM, et al. A phase I trial of intravenous CG7870, a replication-selective, prostate-specific antigen-targeted oncolytic adenovirus, for the treatment of hormone-refractory, metastatic prostate cancer. Mol Ther. 2006;14(1):107-117.

8. Liu TC, Kirn D. Systemic efficacy with oncolytic virus therapeutics: clinical proof-of-concept and future directions. Cancer Res. 2007;67(2): 429-432.

9. Breitbach CJ, Burke J, Jonker D, et al. Intravenous delivery of a multimechanistic cancer-targeted oncolytic poxvirus in humans. Nature. 2011;477(7362):99-102.

10. Bazan-Peregrino M, Rifai B, Carlisle RC, et al. Cavitation-enhanced delivery of a replicating oncolytic adenovirus to tumors using focused ultrasound. J Control Release. 2013;169(1-2):40-47.

11. Okunaga S, Takasu A, Meshii N, et al. Ultrasound as a method to enhance antitumor ability of oncolytic herpes simplex virus for head and neck cancer. Cancer Gene Ther. 2015;22(3):163-168.

12. Pecora AL, Rizvi N, Cohen GI, et al. Phase I trial of intravenous administration of PV701, an oncolytic virus, in patients with advanced solid cancers. J Clin Oncol. 2002;20(9):2251-2266.

13. Lorence RM, Pecora AL, Major PP, et al. Overview of phase I studies of intravenous administration of PV701, an oncolytic virus. Curr Opin Mol Ther. 2003;5(6):618-624.
14. Freeman AI, Zakay-Rones Z, Gomori JM, et al. Phase I/II trial of intravenous NDV-HUJ oncolytic virus in recurrent glioblastoma multiforme. Mol Ther. 2006;13(1):221-228.

15. Shintani M, Takahashi G, Hamada M, Okunaga S, Iwai S, Yura Y. Effect of ultrasound on herpes simplex virus infection in cell culture. Virol J. 2011;8:446.

16. Boucher Y, Baxter LT, Jain RK. Interstitial pressure gradients in tissueisolated and subcutaneous tumors: implications for therapy. Cancer Res. 1990;50(15):4478-4484.

17. Jain RK. Normalization of tumor vasculature: an emerging concept in antiangiogenic therapy. Science. 2005;307(5706):58-62.

18. Bazan-Peregrino M, Carlisle RC, Purdie L, Seymour LW. Factors influencing retention of adenovirus within tumours following direct intratumoural injection. Gene Ther. 2008;15(9):688-694.

19. McKee TD, Grandi P, Mok W, et al. Degradation of fibrillar collagen in a human melanoma xenograft improves the efficacy of an oncolytic herpes simplex virus vector. Cancer Res. 2006;66(5):2509-2513.

20. Wang Y, Yuan F. Delivery of viral vectors to tumor cells: extracellular transport, systemic distribution, and strategies for improvement. Ann Biomed Eng. 2006;34(1):114-127.

21. Passer BJ, Cheema T, Zhou B, et al. Identification of the ENT1 antagonists dipyridamole and dilazep as amplifiers of oncolytic herpes simplex virus-1 replication. Cancer Res. 2010;70(10):3890-3895.

22. Goldberg BB, Gramiak R, Freimanis AK. Early history of diagnostic ultrasound: the role of American radiologists. Am J Roentgenol. 1993; 160(1):189-194.

23. Delalande A, Kotopoulis S, Postema M, Midoux P, Pichon C. Sonoporation: mechanistic insights and ongoing challenges for gene transfer. Gene. 2013;525(2):191-199.

24. Stieger SM, Caskey CF, Adamson RH, et al. Enhancement of vascular permeability with low-frequency contrast-enhanced ultrasound in the chorioallantoic membrane model. Radiology. 2007;243(1):12-21.

25. Zhou S, Li S, Liu Z, et al. Ultrasound-targeted microbubble destruction mediated herpes simplex virus-thymidine kinase gene treats hepatoma in mice. J Exp Clin Cancer Res. 2010;29:170.

26. Carson AR, McTiernan CF, Lavery L, et al. Gene therapy of carcinoma using ultrasound-targeted microbubble destruction. Ultrasound Med Biol. 2011;37(3):393-402.

27. Zhou SJ, Li SW, Wang JJ, et al. High-intensity focused ultrasound combined with herpes simplex virus thymidine kinase gene-loaded ultrasound-targeted microbubbles improved the survival of rabbits with VX(2) liver tumor. J Gene Med. 2012;14(9-10):570-579.

28. Lee YH, Peng CA. Enhanced retroviral gene delivery in ultrasonic standing wave fields. Gene Ther. 2005;12(7):625-633.

29. Greco A, Di Benedetto A, Howard CM, et al. Eradication of therapyresistant human prostate tumors using an ultrasound-guided site-specific cancer terminator virus delivery approach. Mol Ther. 2010;18(2):295-306.

30. Howard CM, Forsberg F, Minimo C, Liu JB, Merton DA, Claudio PP. Ultrasound guided site specific gene delivery system using adenoviral vectors and commercial ultrasound contrast agents. J Cell Physiol. 2006;209(2):413-421.

31. Howard CM. The role of ultrasound contrast agents in gene therapy. Appl Radiol. 2004;33:126-135.

32. Li HL, Zheng XZ, Wang HP, Li F, Wu Y, Du LF. Ultrasound-targeted microbubble destruction enhances AAV-mediated gene transfection in human RPE cells in vitro and rat retina in vivo. Gene Ther. 2009;16(9): $1146-1153$.

33. Carlisle R, Choi J, Bazan-Peregrino M, et al. Enhanced tumor uptake and penetration of virotherapy using polymer stealthing and focused ultrasound. J Natl Cancer Inst. 2013;105(22):1701-1710.

34. Bazan-Peregrino M, Arvanitis CD, Rifai B, Seymour LW, Coussios CC. Ultrasound-induced cavitation enhances the delivery and therapeutic efficacy of an oncolytic virus in an in vitro model. $J$ Control Release. 2012;157(2):235-242.

35. Zhou Y, Yang K, Cui J, Ye JY, Deng CX. Controlled permeation of cell membrane by single bubble acoustic cavitation. J Control Release. 2012;157(1):103-111. 
36. Obrien W Jr. Ultrasound-biophysics mechanisms. Prog Biophys Mol Biol. 2007;93(1-3):212-255.

37. Wu J, Nyborg WL. Ultrasound, cavitation bubbles and their interaction with cells. Adv Drug Deliv Rev. 2008;60(10):1103-1116.

38. Miller DL, Averkiou MA, Brayman AA, et al. Bioeffects considerations for diagnostic ultrasound contrast agents. J Ultrasound Med. 2008;27(4): 611-632; quiz 633-636.

39. Becker H, Burns P. Handbook of Contrast Echocardiography. New York, NY: Spinger-Verlag; 2000

40. de Jong N, Bouakaz A, Frinking P. Basic acoustic properties of microbubbles. Echocardiography. 2002;19(3):229-240.

41. Villanueva FS. Ultrasound mediated destruction of DNA-loaded microbubbles for enhancement of cell-based therapies: new promise amidst a confluence of uncertainties? JACC Cardiovasc Imaging. 2009; 2(7):880-882.

42. Grinstaff MW, Suslick KS. Air-filled proteinaceous microbubbles: synthesis of an echo-contrast agent. Proc Natl Acad Sci U SA. 1991;88: 7708-7710.

43. Sirsi SR, Borden MA. Microbubble compositions, properties and biomedical applications. Bubble Sci Eng Technol. 2009;1(1-2):3-17.

44. Dayton PA, Morgan KE, Klibanov AL, Brandenburger GH, Ferrara KW. Optical and acoustical observations of the effects of ultrasound on contrast agents. IEEE Trans Ultrason Ferroelectr Freq Control. 1999;46:220-232.

45. Hernot $\mathrm{S}, \mathrm{Klibanov} A L$. Microbubbles in ultrasound-triggered drug and gene delivery. Adv Drug Deliv Rev. 2008;60(10):1153-1166.

46. Talu E, Lozano MM, Powell RL, Dayton PA, Longo ML. Long-term stability by lipid coating monodisperse microbubbles formed by a flowfocusing device. Langmuir. 2006;22:9487-9490.

47. Qin S, Caskey CF, Ferrara KW. Ultrasound contrast microbubbles in imaging and therapy: physical principles and engineering. Phys Med Biol. 2009;54(6):R27-R57.

48. Schneider M. SonoVue, a new ultrasound contrast agent. Eur Radiol. 1999;9(3):S347-S348.

49. Lee NG, Berry JL, Lee TC, et al. Sonoporation enhances chemotherapeutic efficacy in retinoblastoma cells in vitro. Invest Ophthalmol Vis Sci. 2011;52(6):3868-3873.

50. Calliada F, Campani R, Bottinelli O, Bozzini A, Sommaruga MG. Ultrasound contrast agents: basic principles. Eur J Radiol. 1998; 27(Suppl 2):S157-S160.

51. Nande R, Claudio PP. Ultrasound contrast agents in cancer therapy. In: Claudio PP, Vogiatzi P, editors. Cutting Edge Therapies for Cancer in the 21st Century. Bussum, Netherlands: Bentham Science Publisher; 2014:425-512.

52. van Wamel A, Kooiman K, Harteveld M, et al. Vibrating microbubbles poking individual cells: drug transfer into cells via sonoporation. J Control Release. 2006;112(2):149-155.

53. Sheikov N, McDannold N, Sharma S, Hynynen K. Effect of focused ultrasound applied with an ultrasound contrast agent on the tight junctional integrity of the brain microvascular endothelium. Ultrasound Med Biol. 2008;34(7):1093-1104.

54. Meijering BD, Juffermans LJ, van Wamel A, et al. Ultrasound and microbubble-targeted delivery of macromolecules is regulated by induction of endocytosis and pore formation. Circ Res. 2009;104(5):679-687.

55. Juffermans LJ, van Dijk A, Jongenelen CA, et al. Ultrasound and microbubble-induced intra- and intercellular bioeffects in primary endothelial cells. Ultrasound Med Biol. 2009;35(11):1917-1927.

56. Kooiman K, Emmer M, Foppen-Harteveld M, van Wamel A, de Jong N. Increasing the endothelial layer permeability through ultrasound-activated microbubbles. IEEE Trans Biomed Eng. 2010;57(1): 29-32.

57. Deng CX, Sieling F, Pan H, Cui J. Ultrasound-induced cell membrane porosity. Ultrasound Med Biol. 2004;30(4):519-526.

58. Kaddur K, Lebegue L, Tranquart F, Midoux P, Pichon C, Bouakaz A. Transient transmembrane release of green fluorescent proteins with sonoporation. IEEE Trans Ultrason Ferroelectr Freq Control. 2010; 57(7):1558-1567.
59. Zhou Y, Kumon RE, Cui J, Deng CX. The size of sonoporation pores on the cell membrane. Ultrasound Med Biol. 2009;35(10): $1756-1760$.

60. Cavalieri F, Zhou M, Tortora M, Lucilla B, Ashokkumar M. Methods of preparation of multifunctional microbubbles and their in vitro/in vivo assessment of stability, functional and structural properties. Curr Pharm Des. 2012;18(15):2135-2151.

61. Liu Y, Miyoshi H, Nakamura M. Encapsulated ultrasound microbubbles: therapeutic application in drug/gene delivery. J Control Release. 2006;114(1):89-99.

62. Cavalieri F, Zhou M, Ashokkumar M. The design of multifunctional microbubbles for ultrasound image-guided cancer therapy. Curr Top Med Chem. 2010;10(12):1198-1210.

63. van Wamel A, Bouakaz A, Versluis M, de Jong N. Micromanipulation of endothelial cells: ultrasound-microbubble-cell interaction. Ultrasound Med Biol. 2004;30(9):1255-1258.

64. Marmottant P, Hilgenfeldt $\mathrm{S}$. Controlled vesicle deformation and lysis by single oscillating bubbles. Nature. 2003;423(6936):153-156.

65. Prentice P, Cuschieri A, Dholakia K, Prausnitz M, Campbell P. Membrane disruption by optically controlled microbubble cavitation. Nature Phys. 2005;1:107-110.

66. Wrenn SP, Dicker SM, Small EF, et al. Bursting bubbles and bilayers. Theranostics. 2012;2(12):1140-1159.

67. Delalande A, Kotopoulis S, Rovers T, Pichon C, Postema M. Sonoporation at low mechanical index. Bubble Sci Eng Technol. 2011;3: $3-11$.

68. Schlicher RK, Radhakrishna H, Tolentino TP, Apkarian RP, Zarnitsyn V, Prausnitz MR. Mechanism of intracellular delivery by acoustic cavitation. Ultrasound Med Biol. 2006;32:915-924.

69. Pan H, Zhou Y, Izadnegahdar O, Cui J, Deng CX. Study of sonoporation dynamics affected by ultrasound duty cycle. Ultrasound Med Biol. 2005;31(6):849-856.

70. Kudo K, Yamamoto K. Behaviour of microbubbles exposed to pulsed ultrasound and their mechanical effect on a cell. In: Proceedings of the 4th National Symposium on Therapeutic Ultrasound. Melville, NY: American Institute of Physics; 2005:211-213.

71. McNeil PL, Terasaki M. Coping with the inevitable: how cells repair a torn surface membrane. Nat Cell Biol. 2001;3(5):E124-E129.

72. Tinkov S, Bekeredjian R, Winter G, Coester C. Microbubbles as ultrasound triggered drug carriers. J Pharm Sci. 2009;98:1935-1961.

73. Mehier-Humbert S, Bettinger T, Yan F, Guy RH. Plasma membrane poration induced by ultrasound exposure: implication for drug delivery. $J$ Control Release. 2005;104(1):213-222.

74. Wei W, Zheng-zhong B, Yong-jie W, Qing-wu Z, Ya-lin M. Bioeffects of low-frequency ultrasonic gene delivery and safety on cell membrane permeability control. J Ultrasound Med. 2004;23(12): 1569-1582.

75. Juffermans LJ, Dijkmans PA, Musters RJ, Visser CA, Kamp O. Transient permeabilization of cell membranes by ultrasound-exposed microbubbles is related to formation of hydrogen peroxide. Am J Physiol Heart Circ Physiol. 2006;291(4):H1595-H1601.

76. Eliasson L, Proks P, Ammälä C, et al. Endocytosis of secretory granules in mouse pancreatic beta-cells evoked by transient elevation of cytosolic calcium. J Physiol. 1996;493(Pt 3):755-767.

77. MacDonald PE, Eliasson L, Rorsman P. Calcium increases endocytotic vesicle size and accelerates membrane fission in insulin-secreting INS-1 cells. J Cell Sci. 2005;118(Pt 24):5911-5920.

78. Paula DM, Valero-Lapchik VB, Paredes-Gamero EJ, Han SW. Therapeutic ultrasound promotes plasmid DNA uptake by clathrinmediated endocytosis. J Gene Med. 2011;13(7-8):392-401.

79. Bao S, Thrall BD, Miller DL. Transfection of a reporter plasmid into cultured cells by sonoporation in vitro. Ultrasound Med Biol. 1997;23(6): 953-959.

80. Miller DL, Thomas RM, Frazier ME. Ultrasonic cavitation indirectly induces single strand breaks in DNA of viable cells in vitro by the action of residual hydrogen peroxide. Ultrasound Med Biol. 1991; 17(7):729-735 
81. Tran TA, Roger S, Le JY, Guennec JY, Tranquart F, Bouakaz A. Mechanisms of cell membrane permeabilization with ultrasound and microbubbles. Ultrason Symp. 2005;32:5-8.

82. Kim HJ, Greenleaf JF, Kinnick RR, Bronk JT, Bolander ME. Ultrasound-mediated transfection of mammalian cells. Hum Gene Ther. 1996;7(11):1339-1346.

83. Rahim A, Taylor SL, Bush NL, ter Haar GR, Bamber JC, Porter CD. Physical parameters affecting ultrasound/microbubble-mediated gene delivery efficiency in vitro. Ultrasound Med Biol. 2006;32(8): 1269-1279.

84. Takaoka H, Takahashi G, Ogawa F, Imai T, Iwai S, Yura Y. A novel fusogenic herpes simplex virus for oncolytic virotherapy of squamous cell carcinoma. Virol J. 2011;8:294.

85. Bayo-Puxan N, Gimenez-Alejandre M, Lavilla-Alonso S, et al. Replacement of adenovirus type 5 fiber shaft heparan sulfate proteoglycanbinding domain with RGD for improved tumor infectivity and targeting. Hum Gene Ther. 2009;20(10):1214-1221.

86. Fisher KD, Green NK, Hale A, Subr V, Ulbrich K, Seymour LW, et al. Passive tumour targeting of polymer-coated adenovirus for cancer gene therapy. J Drug Target. 2007;15(7-8):546-551.

87. Seki T, Carroll F, Illingworth S, et al. Tumour necrosis factor-alpha increases extravasation of virus particles into tumour tissue by activating the Rho A/Rho kinase pathway. J Control Release. 2011;156(3): 381-389.

88. Jain RK, Stylianopoulos T. Delivering nanomedicine to solid tumors. Nat Rev Clin Oncol. 2010;7(11):653-664.

89. Guedan S, Rojas JJ, Gros A, Mercade E, Cascallo M, Alemany R. Hyaluronidase expression by an oncolytic adenovirus enhances its intratumoral spread and suppresses tumor growth. Mol Ther. 2010; 18(7):1275-1283.
90. Homicsko K, Lukashev A, Iggo RD. RAD001 (everolimus) improves the efficacy of replicating adenoviruses that target colon cancer. Cancer Res. 2005;65(15):6882-6890.

91. Vaupel P. Tumor microenvironmental physiology and its implications for radiation oncology. Semin Radiat Oncol. 2004;14(3):198-206.

92. Dash R, Azab B, Shen XN, et al. Developing an effective gene therapy for prostate cancer: new technologies with potential to translate from the laboratory into the clinic. Discov Med. 2011;11(56):46-56.

93. Marty B, Larrat B, Van Landeghem M, et al. Dynamic study of bloodbrain barrier closure after its disruption using ultrasound: a quantitative analysis. J Cereb Blood Flow Metab. 2012;32(10):1948-1958.

94. Vykhodtseva N, McDannold N, Hynynen K. Progress and problems in the application of focused ultrasound for blood-brain barrier disruption. Ultrasonics. 2008;48(4):279-296.

95. Jalali S, Huang Y, Dumont DJ, Hynynen K. Focused ultrasoundmediated BBB disruption is associated with an increase in activation of AKT: experimental study in rats. BMC Neurol. 2010;10:114.

96. Sanches PG, Rossin R, Böhmer M, Tiemann K, Grüll H. Real-time imaging and kinetics measurements of focused ultrasound-induced extravasation in skeletal muscle using SPECT/CT. J Control Release. 2013;168(3):262-270.

97. Hynynen K. Ultrasound for drug and gene delivery to the brain. Adv Drug Deliv Rev. 2008;60(10):1209-1217.

98. Miller DL. Overview of experimental studies of biological effects of medical ultrasound caused by gas body activation and inertial cavitation. Prog Biophys Mol Biol. 2007;93(1-3):314-330.
Oncolytic Virotherapy

\section{Publish your work in this journal}

Oncolytic Virotherapy is an international, peer-reviewed, open access online journal publishing original research, study protocols, reviews, editorials and commentaries on all aspects of oncolytic virology, namely the application of oncolytic viruses for the treatment of cancer. Specific topics in the journal include: Rationale and theoretical aspects of oncolytic virotherapy including in vitro, in vivo and mathematical

Submit your manuscript here: http://www.dovepress.com/oncolytic-virotherapy-journal

\section{Dovepress}

modeling; and practical application and problem solving in the clinic including identification of potential responders through biomarkers and genetic profiling. The manuscript management system is completely online and includes a very quick and fair peer-review system, which is all easy to use. Visit http://www.dovepress.com/ testimonials.php to read real quotes from published authors. 